\title{
Systematic review supports the role of DNA methylation in the pathophysiology of preeclampsia: a call for analytical and methodological standardization
}

A. Cirkovic ${ }^{1}$, V. Garovic ${ }^{2}$, J. Milin Lazovic ${ }^{1}$, O. Milicevic ${ }^{1}$, M. Savic ${ }^{1}$, N. Rajovic ${ }^{1}$, N. Aleksic ${ }^{3}$, T. Weissgerberr, ${ }^{2,4}$ A. Stefanovic ${ }^{5}$ D. Stanisavljevic ${ }^{1+}$ and N. Milic ${ }^{1,2^{*}+}$

\begin{abstract}
Background: Studies have recently examined the role of epigenetic mechanisms in preeclampsia pathophysiology. One commonly examined epigenetic process is DNA methylation. This heritable epigenetic marker is involved in many important cellular functions. The aim of this study was to establish the association between DNA methylation and preeclampsia and to critically appraise the roles of major study characteristics that can significantly impact the association between DNA methylation and preeclampsia.

Main body: A systematic review was performed by searching PubMed, Web of Science, and EMBASE for original research articles published over time, until May 31, 2019 in English. Eligible studies compared DNA methylation levels in pregnant women with vs. without preeclampsia. Ninety articles were included. Epigenome-wide studies identified hundreds of differentially methylated places/regions in preeclamptic patients. Hypomethylation was the predominant finding in studies analyzing placental tissue (14/19), while hypermethylation was detected in three studies that analyzed maternal white blood cells (3/3). In candidate gene studies, methylation alterations for a number of genes were found to be associated with preeclampsia. A greater number of differentially methylated genes was found when analyzing more severe preeclampsia (70/82), compared to studies analyzing less severe preeclampsia vs. controls (13/27). A high degree of heterogeneity existed among the studies in terms of methodological study characteristics including design (study design, definition of preeclampsia, control group, sample size, confounders), implementation (biological sample, DNA methylation method, purification of DNA extraction, and validation of methylation), analysis (analytical method, batch effect, genotyping, and gene expression), and data presentation (methylation quantification measure, measure of variability, reporting). Based on the results of this review, we provide recommendations for study design and analytical approach for further studies. (Continued on next page)
\end{abstract}

\footnotetext{
* Correspondence: milic.natasa@mayo.edu

${ }^{\dagger}$ D. Stanisavljevic and N. Milic contributed equally to this work.

${ }^{1}$ Institute for Medical Statistics and Informatics, Faculty of Medicine, University of Belgrade, Belgrade, Serbia

2Department of Internal Medicine, Division of Nephrology and Hypertension, Mayo Clinic, Rochester, MN, USA

Full list of author information is available at the end of the article
}

C C The Author(s). 2020 Open Access This article is licensed under a Creative Commons Attribution 4.0 International License, which permits use, sharing, adaptation, distribution and reproduction in any medium or format, as long as you give appropriate credit to the original author(s) and the source, provide a link to the Creative Commons licence, and indicate if changes were made. The images or other third party material in this article are included in the article's Creative Commons licence, unless indicated otherwise in a credit line to the material. If material is not included in the article's Creative Commons licence and your intended use is not permitted by statutory regulation or exceeds the permitted use, you will need to obtain permission directly from the copyright holder. To view a copy of this licence, visit http://creativecommons.org/licenses/by/4.0/ The Creative Commons Public Domain Dedication waiver (http://creativecommons.org/publicdomain/zero/1.0/) applies to the data made available in this article, unless otherwise stated in a credit line to the data. 


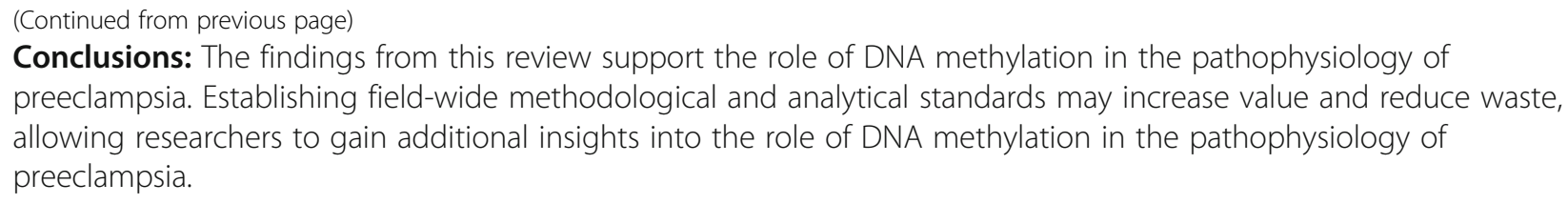

Keywords: Epigenetics, Methylation, Preeclampsia, Meta-research

\section{Introduction}

Preeclampsia (PE) is a life-threatening condition, affecting 2 to $8 \%$ of all pregnancies worldwide [1-3]. It contributes significantly to maternal and fetal morbidity and mortality $[4,5]$. Women with preeclampsia have higher risks for acute renal failure, cerebral bleeding, liver dysfunction, pulmonary edema, and disseminated intravascular coagulation [6]. Well-known risk factors for preeclampsia include antiphospholipid syndrome, previous preeclampsia, insulin-dependent diabetes, multiple pregnancy, nulliparity, family history of preeclampsia, obesity, age over 40 years, and preexisting hypertension $[7,8]$. The exact etiology of PE, however, remains unknown. Study of PE causation is further complicated by the existence of heterogeneous forms of the disease. Preeclampsia is categorized as early or late onset based upon whether gestational age is prior to or after 34 weeks. Early-onset PE (EOPE), compared to late-onset PE (LOPE), is characterized by more severe disease, and commonly presented with severe placental dysfunction and adverse maternal and fetal outcomes, including intrauterine fetal growth restriction [9]. However, it remains poorly understood whether EOPE and LOPE are two different clinical entities that have different pathogenetic mechanisms or represent the same underlying condition of different severity.

Studies recently have examined the role of epigenetic mechanisms in PE pathophysiology. One commonly examined epigenetic process is DNA methylation, a covalent ligation of a methyl group to the $\mathrm{C} 5$ position of the cytosine in a CpG site of DNA by DNA methyltransferases. This heritable epigenetic marker is involved in many important cellular functions including embryonic development, transcription, chromatin structure, and $\mathrm{X}$ chromosome inactivation [10]. A number of studies have explored DNA methylation in PE. Earlier studies have reported global genome methylation profiles in PE [1113] or have examined the methylation level of preselected candidate genes [14-16]. More recently, differentially methylated probes/regions (DMPs/DMRs) between $\mathrm{PE}$ versus controls were identified epigenome-wide using high-throughput platforms [17-19]. While these studies reported hundreds of DMPs and DMRs in the DNA methylome in PE, the results were inconsistent, likely reflecting design limitations, such as the small sample sizes and lack of standardization of the analytical approaches [20]. Moreover, independent replications of key findings were lacking, thus limiting the understanding of epigenetic programming in PE.

Recently published reviews [20-22] have attempted to establish the role of epigenetics in placental development and the etiology of PE, but they did not critically examine the experimental methodologies, closely linked to the accuracy of the results. There has been no systematic review conducted to summarize the relationship between DNA methylation and PE. The aim of this study was to synthesize the evidence regarding the association between DNA methylation and PE and to critically appraise the roles of major study characteristics that can significantly impact the association between DNA methylation and preeclampsia.

\section{Material and methods}

The systematic review was performed in accordance with the Preferred Reporting Items for Systematic Reviews and Meta-Analyses (PRISMA) guidelines and MOOSE Guidelines for Meta-Analyses and Systematic Reviews of Observational Studies [23, 24].

\section{Study selection}

Publications identified were evaluated for inclusion in the study in two phases, and all disagreements were resolved by discussion at each stage. Two reviewers (AC and $\mathrm{OM}$ ) independently reviewed all titles and abstracts and selected the potentially relevant publications. Fulltext copies of the selected publications were obtained and assessed independently by two reviewers according to the study inclusion criteria. We examined studies that compared DNA methylation levels among women who had PE and pregnant women that did not have PE. Studies were eligible for inclusion if DNA methylation was measured in both groups. We excluded studies that (i) investigated other outcomes, (ii) did not include comparisons between pregnant women with vs. without PE, (iii) examined populations other than those with $\mathrm{PE}$, (iv) did not include women but included animals or cell lines, (v) assessed other epigenetic markers, (vi) were abstracts, or (vii) were not original articles. Discrepancies were resolved through a third reviewer. 
In studies for which diagnostic criteria were listed in the paper or provided by the study authors, PE was diagnosed according to accepted guidelines (American College of Obstetricians and Gynecologists, International Society for the Study of Hypertension in Pregnancy, Report of the National High Blood Pressure Program Working Group) [25-27], or using equivalent criteria for hypertension and proteinuria appearing after 20 weeks of gestation.

Studies were stratified into one of the following subgroups:

1. More severe preeclampsia: early-onset preeclampsia (EOPE), severe preeclampsia (sPE)

2. Less severe preeclampsia: late-onset preeclampsia (LOPE), mild preeclampsia (mPE)

3. Not specified preeclampsia: studies without reported severity of preeclampsia

\section{Database search}

Two biostatisticians with expertise in conducting systematic reviews and meta-analyses (NM, AC) developed the search strategy. A systematic review of all published peer-reviewed articles was performed through searches of PubMed, Web of Science (Wos), and EMBASE electronic databases over time, until May 31, 2019. Search queries differed according to the database, and keywords for the PubMed search were preeclampsia and (epigenetic or epigenetics or miRNA or microRNA or DNA methylation or DNA methylations or long non-coding RNA), for Wos: TS $=$ "eclampsia and TS $=$ (epigenetic" or microRNA or DNA methylation or gene imprinting or long non-coding RNA), and for EMBASE: preeclampsia and (epigenetics or microRNA or DNA methylation or genome imprinting or long untranslated RNA). Only publications in English were included. In addition, reference lists of articles identified through electronic retrieval were manually searched, as well as relevant reviews and editorials. Experts in the field were contacted to identify other potentially relevant articles.

\section{Article screening and selection}

Two reviewers (AC, OM) independently evaluated the eligibility of all titles and abstracts. Studies were included in the full-text screening if either reviewer identified the study as being potentially eligible or if the abstract and title did not include sufficient information. Studies were eligible for full-text screening if they included comparisons of DNA methylation levels between women with PE and pregnant women that did not have PE. Preeclampsia included more severe, less severe, and not specified forms. The same reviewers independently performed full-text screening to select articles for inclusion according to the inclusion and exclusion criteria.
Disagreements were resolved by consensus (AC, OM) or arbitration (NM, DS).

\section{Data abstraction and quality assessment}

Two reviewers independently abstracted the following data: author(s), country of research, year of publication, study design, sample size, study population, preeclampsia definitions and type, inclusion and exclusion criteria, sample type and time of DNA collection, epigenetic approach, measures used for DNA methylation level quantification, DNA methylome presentation and reporting, and corresponding gene(s) (with the number of CpGs and region), as well as DNA purification, DNA methylome validation, genotyping, batch effect correction, and mRNA expression. Each reviewer independently evaluated the quality of selected manuscripts using an adapted version of the Newcastle-Ottawa tool for observational studies [28]. Independent reviewers used standardized forms and protocols when selecting and abstracting data. All details regarding study protocol and study characteristics are available at https://osf.io/dv85n/

\section{Statistical analysis}

Data are presented as averages with standard deviations (or standard errors) or medians with ranges for numerical variables. Categorical variables are presented as absolute and relative numbers. Over-representation analysis (ORA) was performed using the PANTHER web tool on the list of gene IDs extracted in the previous steps. The reference database of entities was the Gene Ontology (GO) molecular function complete database, while the reference list of genes was the PANTHER whole-genome list for Homo-sapiens. Fisher's exact test was used with False Discovery Rate (FDR) to correct for multiple testing errors.

\section{Results}

We identified 1346 potentially eligible articles. Upon inspection of the titles and abstracts, 1253 articles were excluded as they were not original articles, were without $\mathrm{PE}$ as the outcome, did not compare PE and control groups, examined populations other than women (animals, cell lines), did not explore methylation levels, or were abstracts. Of the 93 full-text articles that were reviewed, 90 were selected for inclusion in the systematic review. The process of study selection through the different phases of a systematic review is presented in Fig. 1. All 90 full-text publications included in the systematic review are presented in detail in Additional file 1 , which includes tables describing the summary characteristics for the included studies (Table S1), the diagnostic criteria for studies examining women with more 


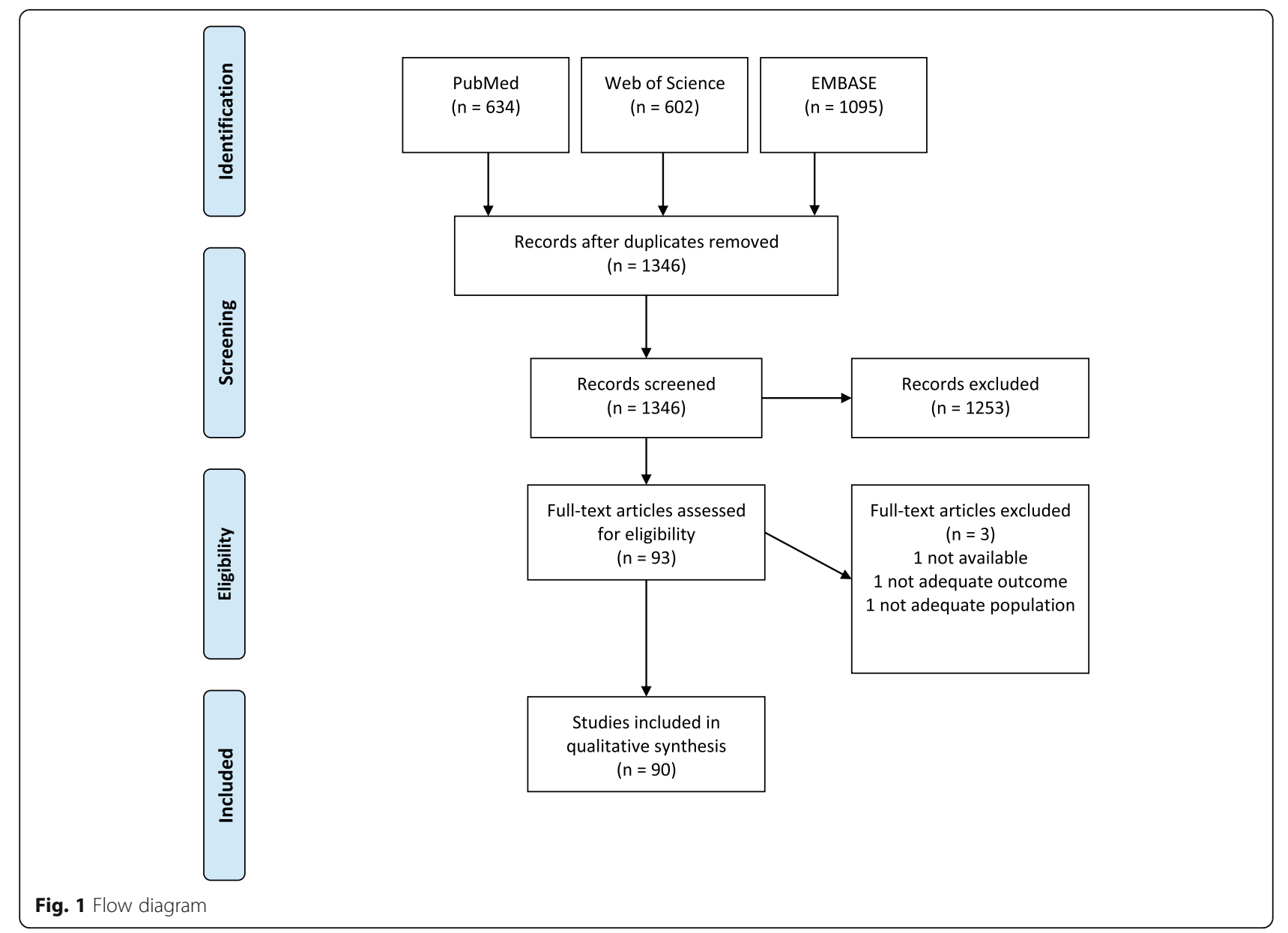

severe and less severe forms of PE (Tables S2, S3), and exclusion criteria in the reviewed studies (Table S4).

\section{Global DNA methylation}

Four studies examined the association between global DNA methylation and PE. Three studies assessed global DNA methylation in the placenta [11-13, 29], while one study assessed DNA methylation using both placenta and umbilical cord blood [29]. Increased global DNA methylation levels in both term and preterm PE placental samples compared to normotensive controls were found in one study [12]. Similarly, another study found that LINE-1 methylation levels were significantly higher in the EOPE placentas compared to normal controls [11]. One study reported no differences in global methylation levels in the placentas of PE and normotensive pregnant women [13]. The study that assessed DNA methylation both in the placental tissue and umbilical cord blood reported lower global methylation levels in placental samples of patients with PE compared to healthy controls, but not in the umbilical cord blood. The overall conclusion, regarding studies that examined global DNA methylation in the placental tissue, is that hyper-, hypo-, and no significant difference in DNA methylation levels were found in PE compared to pregnant women without PE.

\section{Epigenome-wide analysis}

There were 30 studies using an epigenome-wide approach (EWAS) to search for differentially methylated sites associated with PE. Four of them used an EWAS approach only (two studies used the placental tissue, one used the maternal peripheral blood and placenta, and one used the umbilical cord blood and placenta), and 26 studies combined this technique with candidate gene analysis. Twenty-three studies analyzed epigenome-wide methylation levels in the placental tissue; two studies used the maternal peripheral blood (white blood cellsWBC), three studies used the umbilical cord blood, three studies used the omental fat arteries, one study looked at both placental tissue and maternal peripheral blood (WBC), and one study looked at both placental and umbilical cord blood cells (Table 1). All epigenome-wide studies, with the exception of two, reported significant methylation sites, including hyper- and hypomethylation, in patients with $\mathrm{PE}$ compared to pregnant women 
Table 1 Differentially methylated sites in epigenome-wide studies

\begin{tabular}{llll}
\hline $\begin{array}{l}\text { Ref. } \\
\text { no }\end{array}$ & Study & Method & Major findings \\
\hline [17] & $\begin{array}{l}\text { Bourque } \\
2010\end{array}$ & $\begin{array}{l}\text { IlluminaGoldenGateMethylation } \\
\text { Cancer Panel 1 array }\end{array}$ & No significant methylation differences-placenta \\
{$[28]$} & Yuen 2010 & $\begin{array}{l}\text { IlluminaGoldenGateMethylation } \\
\text { Cancer Panel 1 }\end{array}$ & 192 loci differentially methylated (hypo) in the placenta in EOPE, none in LOPE. \\
[30] & Jia 2012 & NimbleGen 385K & $\begin{array}{l}102 \text { genes in total showed significant hypermethylation in the promoter-associated CpG } \\
\text { islands in severe PE placenta tissue samples, while 194 genes showed significant } \\
\text { hypomethylation. }\end{array}$ \\
[31] & $\begin{array}{l}\text { Mousa } \\
\text { 2012a }\end{array}$ & HM 27K & Not reported \\
[32] Mousa & HM 27K & Not reported
\end{tabular}

[33] Mousa HM 27K 2012c

[34] Blair 2013 HM 450K

[35] Hogg HM 450K $2013 a$

[18] White 2013 HM 27K

[36] Anderson HM 450K 2015

[37] Anton 2014 HM 450K

[38] Chu 2014 Infinium microarray (EpityperMassARRAY)

[39] Liu 2014 Methylated-CpG island recovery assay (MIRA)

[40] Blair 2014 HM 450K

[41] Ching 2014 HM 450K

[42] Anderson NimbleGen 2014

[43] Ching 2015 HM 450K

[44] Martin 2015 HM 450K

[45] Zhu 2015 [h]MeDIP with MeDIP-seq

[46] Xuan 2016 NimbleGen

[47] Kim 2016 HM 450K

[48] Wilson HM 450K
$4184 \mathrm{CpG}$ sites (3736 genes) differentially methylated when comparing normal pregnant and preeclamptic omental arteries.

38840 CpG sites with significant differences (282 with > 12.5\% difference) in EOPE in the placenta. The majority (74.5\%) of these sites were hypomethylated in EOPE.

Not reported

PE was associated with widespread differential methylation favoring hypermethylation in maternal peripheral blood (buffy coat). 729 CpGs were hypermethylated, while 268 were hypomethylated in PE, compared to controls.

Significant differences in DNA methylation were identified in 207 individual CpG sites in WBC, $64 \%$ showed a gain, while $36 \%$ were associated with a loss of methylation. The majority of the hypermethylated sites in the WBC also showed varying amounts of methylation gain in the placenta tissue, with many sites showing significant methylation gains in the placenta. Also, the hypomethylated sites in WBC were likely to show a loss of methylation to varying degrees in placental tissue, with many sites showing significant methylation losses.

3411 gene probes (3132 hypermethylated and 279 hypomethylated) were differentially methylated between control and preterm PE ( $<37$ gestational weeks) placentas. A total of 179 gene probes (164 hypermethylated and 15 hypomethylated) were differentially methylated between term PE ( $\geq 37$ gestational weeks) and preterm PE placentas.

49 CpGs significantly altered in EOPE placental tissue compared to normal controls (after excluding X chromosome-specific probes). Seventy-eight percent were hypomethylated in EOPE. Fewer differentially methylated CpGs were also identified when comparing LOPE with controls. Only a single CpG site, MC1R, was found to be differentially methylated between EOPE and LOPE.

8191 (2140 genes) differentially methylated regions were identified in PE placentas compared with controls

Not reported

Of 385,184 useful loci for differential methylation analysis, 9995 showed DM (2.6\%) between EOPE and control placentas. 91.9\% of those DMs (9186 of 9995) were hypermethylated.

Not reported

Hypomethylation pattern in EOPE in umbilical cord blood with 51,486 hypomethylated CPG sites and 12,563 hypermethylated sites.

There were 989 DMPs between the preeclamptic and normotensive placentas. Most (80.7\%) of the DMPs were hypomethylated in the preeclamptic placentas versus the normotensive placentas, while only $19.3 \%$ were hypermethylated.

A total of 714 differential $5 \mathrm{mC}$ peaks (DMRs) were found showing significant differences between late-onset severe PE and controls. Four hundred eighty-seven (68.2\%) had higher $5 \mathrm{mC}$ levels in the late-onset preeclamptic placentas.

1664 promoters with altered DNA methylation, including 663 hypermethylated and 1001 hypomethylated in placental samples.

Maternal peripheral blood showed 71 differentially methylated CpG loci (44 hypermethylated and 27 hypomethylated), while the placenta revealed 365 loci (37 hypermethylated and 328 hypomethylated).

Not reported 
Table 1 Differentially methylated sites in epigenome-wide studies (Continued)

\begin{tabular}{|c|c|c|c|}
\hline $\begin{array}{l}\text { Ref. } \\
\text { no }\end{array}$ & Study & Method & Major findings \\
\hline & 2016 & & \\
\hline [49] & Suzuki 2016 & HELP tagging & $\begin{array}{l}\text { 123, } 85 \text {, and } 99 \text { loci with high-confidence hypertension-associated, proteinuria-associated, and } \\
\text { hypertension- and proteinuria-associated DNA methylation changes in the placenta }\end{array}$ \\
\hline [14] & White 2016 & HM 27K & $\begin{array}{l}\text { Of } 73 \text { analyzed CpGs, } 6 \text { genes were differentially methylated in PE buffy coat compared to } \\
\text { controls }\end{array}$ \\
\hline$[50]$ & Yeung 2016 & HM 450K & $\begin{array}{l}\text { A total of } 303 \text { differentially methylated regions after adjustment for gestational age ( } 214 \\
\text { hypermethylated and } 89 \text { hypomethylated) between preeclampsia cases and controls in the } \\
\text { placenta }\end{array}$ \\
\hline [51] & $\begin{array}{l}\text { Herzog } \\
2017\end{array}$ & HM 450K & $\begin{array}{l}5001 \text { mostly hypermethylated DMPs in the umbilical cord (UC)-WBC and } 869 \text { mostly } \\
\text { hypomethylated DMPs in placental samples. The methylation levels in EOPE UC-WBCs clearly } \\
\text { deviated from those in all other groups. In the comparison of EOPE and PTB, we found } 12040 \\
\text { (28\%) differentially methylated CpGs in UC-WBC and } 5668 \text { (0.5\%) differentially methylated } \\
\text { CpGs in the placenta. One differentially methylated CpG was found in the comparison be- } \\
\text { tween EOPE and uncomplicated controls. No epigenome-wide significant CpGs were found in } \\
\text { the comparisons of LOPE and (un)complicated controls. }\end{array}$ \\
\hline [19] & $\begin{array}{l}\text { Van den } \\
\text { Berg } 2017\end{array}$ & HM 450K & $\begin{array}{l}\text { DNA methylation significantly differed in EOPE compared with spontaneous preterm birth at } 6 \\
\text { CpGs in the placental tissue (hypomethylated), and at } 21 \text { CpGs in UC leukocytes } \\
\text { (hypermethylated). Moreover, significantly different DNA methylation in EOPE compared with } \\
\text { uncomplicated controls was shown at } 6 \text { CpGs in the placental tissue and } 11 \text { CpGs in } \\
\text { uncomplicated controls. No significant associations were shown with LOPE between study } \\
\text { groups or tissues. The most differentially methylated CpGs showed hypomethylation in the } \\
\text { placental tissue and hypermethylation in UC-WBC. }\end{array}$ \\
\hline [52] & Zhao 2017 & HM 450K & $\begin{array}{l}\text { There were } 2667 \text { DMRs ( } 1433 \text { hypermethylated and } 1234 \text { hypomethylated) and } 464 \text { DMIs } \\
\text { between PE and normotensive controls. }\end{array}$ \\
\hline [53] & $\begin{array}{l}\text { Wilson } \\
2018\end{array}$ & HM 450K & $\begin{array}{l}1703 \text { sites were differentially methylated in EOPE vs preterm controls, but only a few changes } \\
\text { were associated with LOPE compared to term controls in the placenta. }\end{array}$ \\
\hline [54] & Wang 2019 & HM 450K & $\begin{array}{l}\text { A total of } 464 \text { probes reached epigenome-wide significance, whilst } 459 \text { (98.9\%) were hypo- } \\
\text { methylated in the EOPE placenta in the Chinese cohort. }\end{array}$ \\
\hline
\end{tabular}

without PE (Table 1). In 14 of 19 studies, hypomethylation was found in the placental tissue, while in three studies, hypermethylation was detected in maternal WBC. Results from the umbilical cord blood studies found the opposite, one reported hypomethylation, while two reported hypermethylation. Five of the epigenomewide studies showed that the methylation profiles differed between early PE patients and controls, but none or fewer differentially methylated sites were found when comparing late-onset PE and controls [19, 28, 38, 51, 53]. Overall, hypomethylation was the predominant finding in epigenome-wide studies (14/19) analyzing the placental tissue, while hypermethylation was detected in three epigenome-wide studies (3/3) that analyzed maternal WBCs.

\section{Gene-specific DNA methylation-candidate gene studies}

For the studies that used candidate-gene approaches, we grouped the findings on DNA methylation and PE according to PE severity. The promoter regions and $\mathrm{CpG}$ islands were frequently targeted in these studies. DNA methylation alterations in PE have been analyzed from different biological tissues. The 13 studies demonstrated that the more severe PE cases, compared to controls, had higher degrees of methylation of $H 19$ [11, 55],
CDH11 [37], TNF [37], LINE-1 [11], Alu [11], NR3C1 [35], CRHBP [35], YWHAQ (T-14-tau) [56], DLL1 [57], NuRD [58], BARX [58], MMP9 [59], and VEGF [60] in placental samples, APC [61], HYP2 [62] in plasma, FAS [43], ACTA2 [43], PI3KR1 [43], MIR145 [43], LOC728264 [43], IL12B [43], MIR24-2 [43] in the umbilical cord blood (UCB) cells, and 15 showed lower methylation levels of NCAM1 [37], INHBA [34], BHLHE40 [34], SLC2A1 [34], ADAM12 [34], TBX15 [43], LEP [63], TERT [48], TNFAIP8 [64], DNMT3A [48], VEGF [60], AKT1 [19], CRTC1 [19], PER1 [19], CSKN1E [19], PRDX1 [19], RORA [19], ARNTL2 [19], CLOCK [19], CRY2 [19], PER2 [19], FOXO3 [19], MAPK1 [19], PRDX5 [19], PRKCA [19], CAPG [28], GLI2 [28], KRT13 [28], TIMP-3 [28], E2F4 [58], C12orf7 [54], PVT1_MIR1204 [54], NDUFAF3 [54], ARSG [54], FYCO1 [54], SULF2 [54], PVT1 [54], OBSL1 [54], MERTK [54], C2 [54], PEBP1 [54], SKI [54], CCDC68 [54] in placental samples, APC [65] in serum, MASPIN [61] in plasma, and MMP1 [32] in omental fat arteries (Table 2). One study showed differences in methylation patterns of CpG sites examined at the DNMT1 [48] (within the same gene cg07627628 was hypomethylated and cg26538782 was hypermethylated). Performing ORA on the genes for severe preeclampsia (including both 
Table 2 DNA methylome alterations in more severe PE cases vs. normotensive controls

\begin{tabular}{|c|c|c|c|c|c|c|}
\hline Gene & No of CpGs & Region & DNA methylation changes & Sample & $P E$ & Reference \\
\hline \multirow[t]{2}{*}{ H19 } & / & I & Hypermethylated & Placenta & EOPE & [11] \\
\hline & 7 & Exon 1 & Hypermethylated & Placenta & sPE & [55] \\
\hline $\mathrm{CDH} 11$ & 1 & / & Hypermethylated & Placenta & EOPE & [37] \\
\hline NCAM1 & 1 & / & Hypomethylated & Placenta & EOPE & {$[37]$} \\
\hline TNF & 1 & / & Hypermethylated & Placenta & EOPE & {$[37]$} \\
\hline INHBA & 1 & $5^{\prime}$ UTR & Hypomethylated & Placenta & EOPE & [34] \\
\hline BHLHE4O & 1 & Body & Hypomethylated & Placenta & EOPE & [34] \\
\hline$S L C 2 A 1$ & 1 & Body & Hypomethylated & Placenta & EOPE & [34] \\
\hline ADAM12 & 1 & Body & Hypomethylated & Placenta & EOPE & [34] \\
\hline LINE-1 & / & / & Hypermethylated & Placenta & EOPE & [11] \\
\hline$T B \times 15$ & 39 & Promoter & Hypomethylated & Placenta & EOPE & [43] \\
\hline Alu & / & / & Hypermethylated & Placenta & EOPE & [11] \\
\hline NR3C1 & Multiple & promoter & Hypermethylated & Placenta & EOPE & [35] \\
\hline$C R H$ & Multiple & 5' UTR & No difference & Placenta & EOPE & {$[35]$} \\
\hline$C R H B P$ & Multiple & Intron 3 & Hypermethylated & Placenta & EOPE & [35] \\
\hline LEP & Multiple & Promoter & Hypomethylated & Placenta & EOPE & [63] \\
\hline TERT & 1 (cg01934390) & I & Hypomethylated & Placenta & EOPE & [48] \\
\hline TNFAIP8 & 1 & / & Hypomethylated & Placenta & EOPE & [64] \\
\hline YWHAQ (T-14-tau)) & 19 & Promoter & Hypermethylated & Placenta & SPE & [56] \\
\hline WNT2 & 7 & Promoter & No difference & Placenta & EOPE & {$[66]$} \\
\hline \multirow[t]{2}{*}{ DNMT1 } & 1 (cg07627628) & / & Hypomethylated & Placenta & EOPE & [48] \\
\hline & 1 (cg26538782) & / & Hypermethylated & & & \\
\hline DNMT3A & 1 (cg11779362) & / & Hypomethylated & Placenta & EOPE & [48] \\
\hline DLL1 & / & Promoter & Hypermethylated & Placenta & EOPE & {$[57]$} \\
\hline NOTCH1 & / & Promoter & No difference & Placenta & EOPE & [57] \\
\hline VEGF & 23 & Promoter & Hypermethylated & Placenta & EOPE & {$[60]$} \\
\hline FLT-1 & 30 & Promoter & No difference & Placenta & EOPE & {$[60]$} \\
\hline$K D R$ & 37 & Promoter & No difference & Placenta & EOPE & [60] \\
\hline AKT1 & 1 & / & Hypomethylated & Placenta & EOPE & [19] \\
\hline CRTC1 & 1 & / & Hypomethylated & Placenta & EOPE & [19] \\
\hline PER1 & 1 & / & Hypomethylated & Placenta & EOPE & [19] \\
\hline CSKNIE & 1 & / & Hypomethylated & Placenta & EOPE & [19] \\
\hline PRDX 1 & 1 & / & Hypomethylated & Placenta & EOPE & [19] \\
\hline RORA & 1 & I & Hypomethylated & Placenta & EOPE & [19] \\
\hline ARNTL2 & 1 & / & Hypomethylated & Placenta & EOPE & [19] \\
\hline CLOCK & 2 & / & Hypomethylated & Placenta & EOPE & [19] \\
\hline CRY2 & 3 & / & Hypomethylated & Placenta & EOPE & [19] \\
\hline PER2 & 4 & / & Hypomethylated & Placenta & EOPE & [19] \\
\hline FOXO3 & 5 & / & Hypomethylated & Placenta & EOPE & [19] \\
\hline MAPK1 & 2 & / & Hypomethylated & Placenta & EOPE & [19] \\
\hline PRDX5 & 1 & / & Hypomethylated & Placenta & EOPE & [19] \\
\hline PRKCA & 2 & / & Hypomethylated & Placenta & EOPE & [19] \\
\hline CAPG & 2 & Promoter & Hypomethylated & Placenta & EOPE & [28] \\
\hline GLI2 & 2 & Promoter & Hypomethylated & Placenta & EOPE & [28] \\
\hline KRT13 & 2 & Promoter & Hypomethylated & Placenta & EOPE & [28] \\
\hline NURD & / & Promoter & Hypermethylation & Placenta & EOPE & [58] \\
\hline BARX & / & Promoter & Hypermethylation & Placenta & EOPE & [58] \\
\hline E2F4 & / & Promoter & Hypomethylation & Placenta & EOPE & [58] \\
\hline
\end{tabular}


Table 2 DNA methylome alterations in more severe PE cases vs. normotensive controls (Continued)

\begin{tabular}{|c|c|c|c|c|c|c|}
\hline Gene & No of CpGs & Region & DNA methylation changes & Sample & $\mathrm{PE}$ & Reference \\
\hline$\overline{M M P 9}$ & 1 & Promoter & Hypermethylation & Placenta & SPE & {$[59]$} \\
\hline C120rf75 & 1 & body & Hypomethylation & Placenta & EOPE & {$[54]$} \\
\hline PVT1_MIR1204 & 1 & TSS200 & Hypomethylation & Placenta & EOPE & {$[54]$} \\
\hline NDUFAF3 & 1 & TSS200 & Hypomethylation & Placenta & EOPE & {$[54]$} \\
\hline ARSG & 1 & body & Hypomethylation & Placenta & EOPE & {$[54]$} \\
\hline FYCO1 & 1 & body & Hypomethylation & Placenta & EOPE & {$[54]$} \\
\hline SULF2 & 1 & $5^{\prime}$ UTR & Hypomethylation & Placenta & EOPE & [54] \\
\hline PVT1 & 1 & body & Hypomethylation & Placenta & EOPE & [54] \\
\hline OBSL1 & 1 & body & Hypomethylation & Placenta & EOPE & {$[54]$} \\
\hline MERTK & 1 & body & Hypomethylation & Placenta & EOPE & {$[54]$} \\
\hline$C 2$ & 1 & 1st exon & Hypomethylation & Placenta & EOPE & [54] \\
\hline PEBP1 & 1 & body & Hypomethylation & Placenta & EOPE & [54] \\
\hline$S K I$ & 1 & body & Hypomethylation & Placenta & EOPE & [54] \\
\hline CCDC68 & 1 & TSS200 & Hypomethylation & Placenta & EOPE & [54] \\
\hline DKK1 & 5 & Promoter & No difference & Placenta & EOPE & {$[66]$} \\
\hline \multirow[t]{2}{*}{ TIMP-3 } & / & / & No difference & Serum & SPE & {$[65]$} \\
\hline & 2 & Promoter & Hypomethylated & Placenta & EOPE & {$[28]$} \\
\hline RASSFIA & / & / & No difference & Serum & SPE & {$[65]$} \\
\hline $\mathrm{CDH1}$ & / & / & No difference & Serum & SPE & {$[65]$} \\
\hline PTGS2 & / & I & No difference & Serum & SPE & {$[65]$} \\
\hline BLT1 & / & / & No difference & Serum & SPE & {$[65]$} \\
\hline \multirow[t]{2}{*}{$A P C$} & / & / & Hypomethylated & Serum & SPE & {$[65]$} \\
\hline & / & / & Hypermethylated & Plasma & SPE & [61] \\
\hline HYP2 & / & / & Hypermethylated & Plasma & EOPE & {$[62]$} \\
\hline MASPIN (SERPINBS) & / & / & Hypomethylated & Plasma & sPE & [61] \\
\hline FAS & 1 & / & Hypermethylated & UCB & EOPE & [43] \\
\hline ACTA2 & 1 & / & Hypermethylated & UCB & EOPE & {$[43]$} \\
\hline PI3KR1 & 1 & / & Hypermethylated & UCB & EOPE & [43] \\
\hline MIR145 & 2 & / & Hypermethylated & UCB & EOPE & [43] \\
\hline LOC728264 & 2 & / & Hypermethylated & UCB & EOPE & {$[43]$} \\
\hline $\operatorname{lL} 12 B$ & 1 & / & Hypermethylated & UCB & EOPE & {$[43]$} \\
\hline IGFI & 1 & / & No difference & UCB & EOPE & {$[43]$} \\
\hline MIR24-2 & 1 & / & Hypermethylated & UCB & EOPE & {$[43]$} \\
\hline MMP1 & 1 & Promoter & Hypomethylated & Omental fat arteries & SPE & {$[43]$} \\
\hline
\end{tabular}

hyper- and hypo-methylation combined) yielded significant results mostly in the transcription factor binding and regulatory DNA sequence $(p<10 \mathrm{e}-5)$. No additional specific molecular pathways stood out as a significant after FDR correction.

Two studies found higher levels of methylation of ACAP2 [45], CLIC6 [45], GATA4 [45], PCDH9 [45], CCDC149 [45], PTPRN2-A [45], PTPRN2-B [45], and RBFOX1 [45], and lower levels of methylation of INHBA [67], BHLHE4O [34], SLC2A1 [34], and PTPRN2-A [45] in the plasma tissue of less severe PE patients compared to normotensive controls (Table 3). For studies without data on PE severity, the list of differentially methylated genes is given in Additional file 1: Table S5. In candidate genes studies, a higher number of differentially methylated genes was found when analyzing more severe PE (70/82), compared to studies analyzing less severe PE vs. controls (13/27).

\section{Methodological study characteristics}

We evaluated methodological study characteristics, including design (number of participants, study design, and PE severity), implementation (biological sample, DNA methylation method, purification of DNA extraction, and validation of methylation), analysis (analytical method, batch effect, genotyping, and gene expression), data presentation (methylation quantification measure, measures of variability, reporting), and major epigenetic 
findings. Ninety eligible articles were identified, including a total of 6197 participants (2536 PE vs. 3661 controls). Preeclampsia severity was reported in 35 studies. Women with less severe PE were included in 18 studies, while women with more severe PE were included in all 35 studies. There were eighteen case-control studies, with a total of 2219 cases and 2671 controls. The most frequent study design was cross-sectional $(n=62)$. The remaining studies were nested case-control (five studies), and four prospective cohorts which included 107 participants. Participants were matched in $30 \%$ of studies, most often by gestational age (15/27) (Additional file 1: Table S1). In only six studies, participants with PE and those in the control group were matched by maternal age (Additional file 1: Table S1). In four studies, an analytical approach (ANCOVA, regression analysis) was applied to control for confounding variables. Women's ethnicities were reported in 18 studies. Homogeneous ethnic groups were identified in three studies, and adjustment for this factor was applied in five studies. Fetal gender was considered as an important factor influencing the DNA methylome in 15 studies [13, 28, 29, 34, 38, 40, 41, $43,48-50,53,63,68,69]$. In nine studies, all probes on the $\mathrm{X}$ chromosome were excluded; in two studies, the genders were analyzed separately, and in five studies, adjusting for fetal gender was applied.

Table 4 summarizes the implementation characteristics of the studies included in this review. The most commonly applied time of sampling in both groups was at delivery, which was reported in 82 (91\%) studies, except for seven of these studies in which the time of sampling in the control group was reported as the time of abortion, including abortions in the 1st and 2nd trimesters of pregnancy. The frequency of sampling before

Table 3 DNA methylome alterations in less severe PE cases vs. normotensive controls

\begin{tabular}{|c|c|c|c|c|c|c|}
\hline Gene & No of CpGs & Region & DNA methylation changes & Sample & $P E$ & Reference \\
\hline COL5A1 & 1 & I & No difference & Placenta & LOPE & {$[37]$} \\
\hline INHBA & 2 & $5^{\prime}$ UTR & Hypomethylated & Placenta & LOPE & [34] \\
\hline BHLHE4O & 1 & Body & Hypomethylated & Placenta & LOPE & [34] \\
\hline$S L C 2 A 1$ & 1 & Body & Hypomethylated & Placenta & LOPE & [34] \\
\hline ADAM12 & 1 & Body & No difference & Placenta & LOPE & {$[34]$} \\
\hline LINE-1 & / & / & No difference & Placenta & LOPE & [11] \\
\hline Alu & / & / & No difference & Placenta & LOPE & [11] \\
\hline $\mathrm{CRH}$ & Multiple & $5^{\prime}$ UTR & No difference & Placenta & LOPE & [35] \\
\hline CRHBP & Multiple & Intron 3 & No difference & Placenta & LOPE & [35] \\
\hline LEP & Multiple & Promoter & No difference & Placenta & LOPE & [63] \\
\hline \multirow[t]{2}{*}{ TERT } & 1 (cg01934390) & Promoter & No difference & Placenta & & [48] \\
\hline & 1 (cg11832804) & Promoter & & & LOPE & \\
\hline \multirow[t]{2}{*}{ DNMT1 } & 1 (cg07627628) & / & No difference & Placenta & & [48] \\
\hline & 1 (cg26538782) & / & & & LOPE & \\
\hline NOTCHI & / & Promoter & No difference & Placenta & LOPE & [57] \\
\hline VEGF & 23 & Promoter & Hypomethylated & Placenta & LOPE & {$[60]$} \\
\hline FLT-1 & 30 & Promoter & No difference & Placenta & LOPE & {$[60]$} \\
\hline$K D R$ & 37 & Promoter & No difference & Placenta & LOPE & {$[60]$} \\
\hline ACAP2 & 4 & Promoter & Hypermethylated & Placenta & LOPE & [45] \\
\hline CLIC6 & 11 & Promoter & Hypermethylated & Placenta & LOPE & [45] \\
\hline GATA4 & 9 & Promoter & Hypermethylated & Placenta & LOPE & [45] \\
\hline PCDH9 & 7 & Promoter & Hypermethylated & Placenta & LOPE & [45] \\
\hline PTPRN2-A & 20 & Promoter & Hypomethylated & Placenta & LOPE & [45] \\
\hline CCDC149 & / & Promoter & Hypermethylated & Placenta & LOPE & [45] \\
\hline PTPRN2-A & / & Promoter & Hypermethylated & Placenta & LOPE & [45] \\
\hline PTPRN2-B & / & Promoter & Hypermethylated & Placenta & LOPE & [45] \\
\hline RBFOX1 & / & Promoter & Hypermethylated & Placenta & LOPE & [45] \\
\hline MASPIN (SERPINB5) & / & / & No difference & Plasma & $\mathrm{mPE}$ & [61] \\
\hline MMP1 & 1 & Promoter & No difference & Omental fat arteries & $\mathrm{mPE}$ & [32] \\
\hline
\end{tabular}


Table 4 Implementation characteristics of studies

\begin{tabular}{|c|c|c|}
\hline Characteristics & $n$ & $\%$ \\
\hline \multicolumn{3}{|l|}{ Time of sampling } \\
\hline At the time of delivery & 82 & 91.1 \\
\hline Before delivery & 13 & 14.4 \\
\hline After delivery & 5 & 5.5 \\
\hline At the time of abortion & 7 & 7.8 \\
\hline Not reported & 7 & 7.8 \\
\hline \multicolumn{3}{|l|}{ Sample } \\
\hline Placenta & 75 & 83.3 \\
\hline \multicolumn{3}{|l|}{ Maternal peripheral blood } \\
\hline Plasma & 9 & 10.0 \\
\hline Serum & 2 & 2.2 \\
\hline White blood cells (WBC) & 9 & 10.0 \\
\hline Lymphocytes & 1 & 1.1 \\
\hline Whole maternal blood & 1 & 1.1 \\
\hline Umbilical cord blood & 7 & 7.8 \\
\hline Omental fat arteries & 3 & 3.3 \\
\hline Placental vessels & 1 & 1.1 \\
\hline Umbilical vein & 1 & 1.1 \\
\hline \multicolumn{3}{|l|}{ Targeted genetic locations } \\
\hline Global DNA-methylation & 5 & 5.5 \\
\hline Genome-wide & 4 & 4.5 \\
\hline Genome-wide, selected genes for replication & 25 & 27.8 \\
\hline Candidate gene(s) & 58 & 64.4 \\
\hline \multicolumn{3}{|l|}{ DNA methylation method (most frequent) } \\
\hline Illumina27+|llumina450 & 21 & 23.3 \\
\hline Bisulfite sequencing & 23 & 25.5 \\
\hline Bisulfite pyrosequencing & 19 & 21.1 \\
\hline Methylation specific PCR & 11 & 12.2 \\
\hline Purification of DNA extraction & 33 & 36.7 \\
\hline Validation of methylation & 30 & 33.3 \\
\hline
\end{tabular}

delivery was $14 \%$, while five studies reported sampling after delivery. The time of sampling was not reported in seven of the studies. Placental samples were the most common studied tissues, as they were used for DNA methylome profiling in 75 studies (83\%). Of 25 studies in which the maternal peripheral blood was sampled, plasma samples were used in nine studies, serum samples in two studies, WBC in nine studies, and lymphocytes in only one study. In a small number of studies, DNA methylation was assessed from the umbilical cord blood cells or omental fat arteries (seven and three studies, respectively). Two studies used the vessels as samples (one placental vessel and one umbilical vein). Fiftyeight studies used the candidate-gene approach and 34 examined the whole genome. Sequencing-based methods were widely used to quantify levels of DNA methylation across all studies. The most frequently reported was bisulfite sequencing (25\%), followed by bisulfite pyrosequencing, which was used in $21 \%$ of studies. Genomewide microarray technologies, such as Illumina27, Illumina 450 , or Illumina HiSeq2500, were used in $23 \%$ of the reviewed studies. All other methods were reported in a small number of studies. Almost $40 \%$ of these studies checked DNA purification (33/90), but there were fewer that included methylation validation (30/90).

Data were analyzed using both parametric and nonparametric tests. Batch-effect correction was found in 9 studies only. Only seven studies performed genotyping, while more than half $(61 / 90)$ conducted gene-expression studies.

A high degree of heterogeneity existed among the studies in terms of data presentation (Table 5). In more than one-half of these studies, the mean DNA methylation level was reported using a percentage value. $\beta$ values were found in 19 studies, and $\Delta \beta$ values were reported in 15 of the reviewed studies. One-half of the studies (56\%) reported a measure of variability (standard deviation-sd, standard error-se, 95\% confidence interval-95\%CI, interquartile range-iqr, range) for the level of DNA methylation in each group. Also, individual data were found in a small number of studies (14\%). Values for the DNA methylation level were commonly graphically presented (78\%), and only one third of the reviewed studies reported mean levels of DNA methylation in their tables. Most importantly, we found row data stored in a Gene Expression Omnibus repository for only eleven of the studies included in this review $[18,34,35$, $37,40,44,49-51,53,70]$.

\section{Discussion}

This systematic review aimed to summarize the findings on the association between DNA methylation and preeclampsia and to explore the major study characteristics that can significantly impact this association. Overall, altered methylation (hyper- and hypo-) on the promoter regions and $\mathrm{CpG}$ islands of a number of genes were found in both more and less severe forms of PE, and hundreds of DMPs/DMRs were identified in the studies that examined the whole genome. A high degree of heterogeneity existed among the studies in terms of methodological study characteristics.

\section{Association between DNA methylation and preeclampsia} Global methylation levels were evaluated in different tissues with inconsistent conclusions. Placental global hypomethylation in normal pregnancy changes throughout gestation [71, 72]. LINE-1 (Long Interspersed Nucleotide Element 1) serves as a surrogate for global DNA methylation levels [73]. This systematic review showed that LINE-1 was hypermethylated in placentas from early- 
Table 5 Data presentation

\begin{tabular}{|c|c|c|}
\hline Data presentation & $n$ & $\%$ \\
\hline \multicolumn{3}{|l|}{ Methylation quantified by } \\
\hline$\beta$ value & 19 & 21.1 \\
\hline$\Delta \beta$ & 15 & 16.7 \\
\hline Adjusted $\Delta \beta$ & 1 & 1.1 \\
\hline$\Delta \beta$ fold change & 1 & 1.1 \\
\hline Fold change & 4 & 4.5 \\
\hline Relative fold change & 1 & 1.1 \\
\hline $\log _{2}$ ratio & 7 & 7.8 \\
\hline $\log _{2}$ fold change & 1 & 1.1 \\
\hline$\%^{*}$ & 71 & 78.9 \\
\hline$M$ value (logit transformed $\beta$ ) & 3 & 3.3 \\
\hline Diff score & 1 & 1.1 \\
\hline $\mathrm{Ct}(\Delta \mathrm{Ct}, 2-\Delta \mathrm{Ct})$ & 2 & 2.2 \\
\hline H-score & 1 & 1.1 \\
\hline Positive for methylation & 1 & 1.1 \\
\hline Number of copies/mL & 2 & 2.2 \\
\hline Error presented (sd, se, iqr, $95 \% \mathrm{Cl}$, range) & 50 & 55.5 \\
\hline Individual data & 13 & 14.4 \\
\hline \multicolumn{3}{|l|}{ Methylation reported in } \\
\hline \multicolumn{3}{|l|}{ Main text } \\
\hline Table & 36 & 40.0 \\
\hline Figure & 70 & 77.8 \\
\hline In text only & 2 & 2.2 \\
\hline Supplement & 17 & 18.9 \\
\hline Not reported at all & 1 & 1.1 \\
\hline Repository & 11 & 12.2 \\
\hline
\end{tabular}

$\beta$ value is an estimate of methylation level using the ratio of intensities between methylated and unmethylated alleles $\beta=$ methylated allele intensity $(M) /($ unmethylated allele intensity $(U)+$ methylated allele intensity $(M)+100)$; $*$, mean methylation $\%, \%$ change in methylation, $\%$ of methylated/ unmethylated, \% hypermethylated; using the Illumina Custom Algorithm a Diff score is calculated from the $p$ value of significance: DiffScore $=(10 \mathrm{sgn}$ (IcondIref) $\left.\log _{10}(p)\right) ; C t$ value is a relative measure of DNA methylation level that denotes which cycle the fluorescence goes over a certain threshold value; $\mathrm{H}$ score is the product of the percentage of cells in each sample with positive staining (range, $0-100 \%$ ) multiplied by the intensity of staining (range, $0-3$ ); sd, standard deviation; se, standard error; iqr, interquartile range

onset PE patients, without significant difference in lateonset PE, compared to healthy pregnant women's placentas. This finding could explain the fluctuation of DNA methylation levels during pregnancy trimesters and also the differences in PE phenotypes. In that context, Myatt and coworkers suggested the use of preterm deliveries as an adequate control group for early-onset PE [74].

EWAS found significant methylation sites, including hyper- and hypomethylation. The majority of the studies analyzed DNA methylation levels in the placenta, and $73 \%$ of them reported significant hypomethylation sites.
In addition, the methylation profiles for EOPE and LOPE were reported to be different, thus suggesting distinct phenotypes [75]. However, the observed methylation difference may be due to differences in gestational age between these two forms of PE. The availability of control placentas throughout gestation facilitates making distinctions between the effects of gestational age and those related to PE subtype. Additional limitations of published studies include the cellular complexity of the examined tissues, with more than one cell type commonly being present in the examined samples, and the various statistical tests that were utilized. Furthermore, studies rarely included replication cohorts. Konwar et al. suggested that addressing the abovementioned aspects would facilitate the reproducibility and integration of results across placenta studies when processing and interpreting genomics data [76].

While DNA methylation changes of candidate genes in placental and other tissues have been confirmed by EWAS, only a few new loci of interest have been discovered [34, 37, 59]. Blair et al. reported four genes relevant to preeclampsia (INHBA, BHLHE40, SLC2A1, and ADAM12), with different degrees of methylation changes in LOPE compared to EOPE [34]. Previous studies have shown that BHLHE40 [77] and SLC2A1 [78] expressions can be affected by hypoxia, while INHBA and ADAM12 [79] are relevant to prenatal screening. One study [35] showed increased DNA methylation at $\mathrm{CpG}$ sites within genes encoding the glucocorticoid receptor (NR3C1) and CRH binding protein (CRHBP) in EOPE-associated placentas, but not in LOPE compared to controls. In the same study, significant hypomethylation was observed in EOPE, but not in LOPE placentas for the TEA domain family member 3 (TEAD3) and CYP19 [35]. The same authors in another publication found that the DNA methylome level of the LEP gene promoter was hypomethylated in EOPE, but not in LOPE [63]. Robinson et al. reported that after adjusting for fetal sex and gestational age, DNA methylation at $\operatorname{cg} 01934390$ within TERT and $\operatorname{cg} 26538782$ within DNMT1 differed between EOPE and controls, and no difference was observed between LOPE and controls [48]. The results of Sundrani et al. showed a significantly lower mean methylation level of the vascular endothelial growth factor (VEGF) promoter, an important mediator in many endothelial and extravascular processes, in the preterm PE group compared to the normotensive group $[60,80]$. They showed significantly reduced mean methylation at the CpG site 6, 7, and CpG site 8, and significantly higher methylation at CpG site 14 [60]. Also, the mean methylation at CpG site 16 in the FLT-1 (VEGFR1-vascular endothelial growth factor receptor) promoter region was significantly reduced in the term PE group compared to the normotensive group, while 
mean methylation at $\mathrm{CPG}$ site 17 was significantly reduced in the preterm PE group compared to the normotensive group [60]. Qi et al. found that the u-maspin (or SERPINB5 gene) $\Delta$ Ct value was significantly lower in women with severe PE compared to those with a normal 3rd-trimester pregnancy, and no difference was found between women with mild PE and those with a normal 3rd-trimester pregnancy [61]. Mousa et al. reported a significant decrease in methylation in the promoter region of the MMP1 gene in the omental arteries of women with severe PE compared to normal pregnant women, but methylation at the same site was not significantly different in the arteries obtained from women with mild PE compared to the arteries from normal pregnant women [32]. Although methylations are found mostly in the regulatory (promoter and enhancer) regions of genes, the fact that the genes themselves are transcription factors indicates that preeclampsia is a multi-level regulatory disturbance with widespread genomic effects rather than affecting a singular pathway.

\section{Study characteristics}

The basic necessary step for the realization of quality research is defining a clear understandable hypothesis referring to the specific disease phenotype [81]. Clear conclusions are expected to be found in a more specific form of the disease (more or less severe preeclampsia), because of the differences in etiology, pathophysiology, course, and also the prognosis of the disease [82]. A good hypothesis should be followed by an adequate epidemiological study design. The majority of reviewed studies were retrospective, while a more appropriate, nested case-control with a prospective cohort design [83] was used in just nine studies. The major reason for recommending a prospective study design is to avoid a list of potential confounders [83, 84]. Many environmental (chemical exposure, nutrition) and lifestyle characteristics (smoking, alcohol, and drug consumption) [85, 86] can influence the strength or even change the direction of associations between DNA methylation (global or site specific) and preeclampsia. The most important factor, gestational age, strongly influences the DNA methylation level in placental samples [87]. DNA methylation level is also related to maternal age [88] and the risk for developing PE $[78,89]$. However, only six studies were participants matched for maternal age or an adequate method employed to control for maternal age. Fetal gender also influences DNA methylation level, and previous findings have shown that there is a sexual epigenetic dimorphism of the placental DNA methylome [90]. Tissue samples from pregnancies with a female fetus have a larger number of differentially methylated loci [32], suggesting the importance of considering fetal gender when assessing the DNA methylation level in pregnant women.
Most of the included studies had disadvantages in terms of scarcity of patient characteristics, preeclampsia definitions, and reporting of inclusion and exclusion criteria. Comprehensive data on patient characteristics as potential confounders are of great importance for obtaining accurate conclusions. The variety of reported PE definitions found in the reviewed studies does not allow for generalization of the conclusions. Although more (early/severe) and less (late/mild) severe PE may have different epigenetic pathophysiologies, disease severity was reported in fewer than half of the studies. Complete or incomplete data on pre-existing hypertension, previous history of $\mathrm{PE}$, positive family history for hypertensive disorders in pregnancy, other cardiovascular diseases, renal diseases, and diabetes mellitus or additional inclusion or exclusion criteria were reported in 66 (73\%).

The tissue specificity of the epigenome pattern adds another challenge to the design of DNA methylation studies in preeclampsia. DNA methylation level was analyzed predominantly in the placental tissue $(83.3 \%)$ rather than in extra-embryonic membranes (amniotic and chorionic). The placenta is a dynamically changing organ. Fine-tuning sensitive mechanisms such as angiogenesis and the fetal-maternal interface and adequate cytotrophoblast invasion with the remodeling of the spiral arteries are crucial for physiological placentation. Adverse pregnancy outcomes, such as preeclampsia, could be the results of these processes [91]. In an effort to improve reporting standards in studies of human placenta, the use of a consistent sampling location and focusing on a specific cell type have been recommended [84]. Maternal peripheral blood was sampled in $27.8 \%$ of studies. Plasma was the most commonly analyzed of all blood derivatives (in 36\%). Specific types of blood cells were rarely used for DNA methylation analysis in PE. Purified samples consisting only of a single-cell type have been recommended instead of mixed cell samples [81]. To date, limited or no work has addressed the stability and correlation of DNA methylation patterns in different blood products, as they relate to preeclampsia. Differences in DNA methylation levels between PE and normotensive women [18], as well as changes in DNA methylation levels during normal and pathologic pregnancies within the same tissue type [14, 92] were reported. The importance of sample specificity is further reflected in the presence of proven differences in methylation levels within different tissue types in preeclampsia, such as hypermethylation in umbilical cord-WBCs and hypomethylation in the placental tissue in EOPE vs. preterm normotensive controls [51]. Because cell specificity has been ignored in most methylation studies, it is difficult to interpret results and draw meaningful conclusions. Tissue specificity of epigenetic patterns and 
heterogeneity in sample collection are just some of the obstacles that have hindered progress in identifying mechanisms involved in the pathogenesis of PE and identifying relevant clinical applications.

DNA methylation as a potential mechanism of transcription and gene expression changes could be evaluated in blood cellular components during pregnancy, at the time of a PE diagnosis or after delivery. The time of sampling is indicated by the type of the sampled tissue. The timing to obtain the clinically most relevant result would theoretically be before diagnosis, as early as possible during pregnancy. Scientific relevance, on the other hand, can be demonstrated regardless of the timing of tissue sampling, in order to explore the changing of DNA methylation levels involved in PE pathogenesis.

The methodology used for methylation analysis varied among the studies. Mostly, well-established techniques such as bisulfite polymerase chain reaction (PCR) and pyrosequencing or $27 \mathrm{~K}$ or $450 \mathrm{~K}$ BeadChip arrays were performed. Choosing an adequate technique depends on the aim of the study, the amount and quality of the DNA sample, the sensitivity and specificity required in the study, and the needed robustness of the method, as well as availability of software, equipment, reagents, and also costs. For many years, bisulfite sequencing PCR (BSP) has been the "gold standard" for measuring DNA methylation, although this method is not able to distinguish methylcytosine $(5-\mathrm{mC})$ from cytosine [73]. The ability of pyrosequencing to reliably detect differences in DNA methylation, using previously designed primers, across cell populations without requiring the cloning of bisulfite-treated DNA, is a major advantage of this technique $[93,94]$. It is a good technique for heterogeneous samples, where only a fraction of cells has a differentially methylated gene of interest [73]. Because of its timesaving and cost-efficiency, ability to analyze many identified sites, and also quantitative accuracy and reproducibility, HM450 has become the most widely used epigenotype-mapping tool. Cross-reactive probes, SNPaffected probes, within-array bias (Infinium I and II bias), and between-array bias (batch effects) are important weaknesses inherent with the use of HM450 epigenotype mapping, especially when subtle methylation differences need to be detected by statistical tests between large numbers of cases and controls $[95,96]$. Recently, newly introduced sophisticated methods, such as next-generation sequencing (NGS), present a huge potential for future research [97].

More than half of the reviewed studies used a candidate gene approach. DNA purification and DNA methylation validation of findings across multiple independent samples or cohorts are crucial for accurate results. Purification of extracted DNA was performed in fewer than half of the studies. A small number of studies performed validation, in the same or a separate study population. Although batch effects (differences between study groups caused by the heterogeneity of laboratory conditions, reagents, and respondent characteristics) may bias methylation study results, they were corrected in only 9 studies. Not controlling for batch effects remains a significant problem that leads to incorrect conclusions. It is recommended that SNP (single-nucleotide polymorphism) genotyping be performed in order to obtain more precise conclusions. This process is not only important for GWAS studies, but also for epigenome studies [98]. It can help in finding a specific genotype associated with a specific methylation level change in PE. Only half of the reviewed studies analyzed correlations between methylation alterations and gene expression. As geneexpression determines whether the association between DNA methylation and PE represents a true biological effect, future methylation studies should assess gene expression.

There was an effort to standardize methodology reporting after 2011, but it has not been sustained. Purification of extracted DNA and gene-expression have often been reported in articles published during the last few years, but data for genotyping and controlling for batch effects are still insufficient. The deposition of data in repositories began in 2013, but it is still a rare practice, being found in only a small number of the included studies.

Improved and standardized reporting of DNA methylation should be necessary for the identification of epigenetic-based effects in preeclampsia. Methylation levels were commonly reported using percentage values and $\beta$ values as recommended [73], but often in figures only and without an accompanying measure of variability. A small number of studies included individual data and deposited raw data in open repositories. It is recommended that DNA methylation results should be presented in tables using the arithmetic mean with standard deviation or median with range or an interquartile range. In view of new attitudes towards better data reproducibility, it is also recommended that raw data should be saved in on-line repositories [84].

The findings of this review support the role of DNA methylation in the pathophysiology of preeclampsia. In candidate gene studies, methylation alterations for a number of genes were found to be associated with PE. EWAS identified hundreds of DMPs/DMRs in preeclamptic patients, further supporting the abnormality of the DNA methylome in PE. However, methodological problems found in the reviewed studies make it difficult to draw definitive conclusions regarding the association between DNA methylation and preeclampsia. Establishing field-wide methodological and analytical standards for rigorous and reproducible study designs, sample 
processing and data analyses may increase value and reduce waste, allowing researchers to gain additional insights into the role of DNA methylation in the pathophysiology of preeclampsia. As a result of the current review, we suggest that future epigenetic studies of methylation in preeclampsia consider the following recommendations:

- Utilize a prospective (cohort) or conceivably a nested case control within a cohort rather than a retrospective study design

- Define preeclampsia according to the recommended guidelines and take into account disease severity, i.e., EOPE, LOPE, mPE, and sPE

- When defining the control group, take into account gestational age, the health status of the target population (healthy or without hypertensive pregnancy disorders/PE), inclusion/exclusion of women with chronic hypertension

- Account for confounders, i.e., maternal age, gestational age, parity, ethnicity, fetal gender, comorbidities, environmental (chemical exposure, nutrition), and lifestyle characteristics (smoking, alcohol, and drug consumption)

- Choose an appropriate tissue and control for cellular heterogeneity, i.e., choose a tissue that allows for individual cell counts and/or computational correction. Analyze changes in methylation level over time, i.e., maternal peripheral blood in the 1st, 2nd or 3rd trimester, at the time of delivery, after delivery

- Report details about the purification of the extracted DNA molecule

- Epigenome-wide approaches using a bead chip may be useful for hypothesis generation (larger sample sizes likely required)

- Targeted bisulfite sequencing may be useful to capture DNA methylation in a focused region for a specific hypothesis-driven approach addressing a specific biological question, thus allowing for comprehensive methylation analyses of a particular site

- Include a validation cohort, preferably from a different population

- Plan to analyze gene expression to evaluate the effect of methylation

- Choose an adequate methylation quantification measure and report exact values with the appropriate measure of variability, i.e., arithmetic mean with standard deviation, median with range or interquartile range

- Report details as to the applied specific analytical methods

- Be transparent in data presentation and store row data in open repositories
- Minimize unseen variation by reporting all the relevant metadata and labeling technical batches

\section{Perspectives and significance}

Increased collaboration within the scientific community aiming to establish field-wide methodological and analytical standards may allow additional insights into the role of DNA methylation in the pathophysiology of preeclampsia. Sharing of public datasets, with the inclusion of sampling protocols, relevant technical variables, such as DNA quality assessment, batch/chip design maps, pre-processed data, and confounders, may provide sufficient sample sizes, allowing for definitive conclusions about the association between DNA methylation and preeclampsia.

\section{Supplementary information}

Supplementary information accompanies this paper at https://doi.org/10. 1186/s13293-020-00313-8

Additional file 1: Table S1. Summary of Studies included in the systematic review; Table S2. Definitions of preeclampsia; Table S3. Criteria for less severe and more severe forms of preeclampsia; Table S4. Exclusion criteria for studies examining DNA methylation between preeclamptic and normotensive women; Table S5. Differentially methylated genes in not specified PE.

Abbreviations

PE: Preeclampsia; EOPE: Early-onset preeclampsia; LOPE: Late-onset preeclampsia; DMPs: Differentially methylated probes; DMRs: Differentially methylated regions; SPE: Severe preeclampsia; mPE: Mild preeclampsia

\section{Acknowledgements}

Dr Natasa Milic is funded as a BIH QUEST Visiting Fellow.

Authors' contributions

Conceptualization: AC, VG, AS, DS, NM; Data curation: AC, JML, OM, MS, NR, NA; Formal analysis: AC, JML, OM, MS, NR, DS, NM; Investigation: AC, VG, JML, OM, MS, NR, NA, TW, AS, DS, NM; Methodology: AC, VG, JML, TW, AS, DS, NM; Project administration: VG,DS, NM; Supervision: VG, AS, DS, NM; Visualization: AC, JML, MS, TW, DS, NM; Writing —original draft: AC, VG, JML, OM, MS, NR, $N A, T W, A S, D S, N M$; Writing — review \& editing: AC, VG, JML, OM, MS, NR, NA TW, AS, DS, NM. The authors read and approved the final manuscript.

Funding

R01-HL136348(VDG)

\section{Availability of data and materials}

All data generated or analyzed during this study are included in this published article [and its supplementary information files].

Ethics approval and consent to participate Not applicable

Consent for publication

Not applicable

\section{Competing interests}

The authors declare that they have no competing interests.

\section{Author details}

IInstitute for Medical Statistics and Informatics, Faculty of Medicine, University of Belgrade, Belgrade, Serbia. ${ }^{2}$ Department of Internal Medicine, Division of Nephrology and Hypertension, Mayo Clinic, Rochester, MN, USA. ${ }^{3}$ Center for Molecular Biology, University of Vienna, Vienna, Austria. ${ }^{4}$ Charité - 
Universitätsmedizin Berlin, Berlin Institute of Health, QUEST Center, Berlin, Germany. ${ }^{5}$ Clinic for Gynecology and Obstetrics, Clinical Centre of Serbia, Belgrade, Serbia.

Received: 11 February 2020 Accepted: 18 June 2020

Published online: 06 July 2020

\section{References}

1. Garovic VD, White WM, Vaughan L, et al. Incidence and long-term outcomes of hypertensive disorders of pregnancy. J Am Coll Cardiol. 2020; 75(18):2323-34.

2. Hutcheon JA, Lisonkova S, Joseph KS. Epidemiology of pre-eclampsia and the other hypertensive disorders of pregnancy. Best Pract Res Clin ObstetGynaecol. 2011;25(4):391-403.

3. Hauth JC, Ewell MG, Levine RJ, Esterlitz JR, Sibai B, Curet LB, et al. Pregnancy outcomes in healthy nulliparas who developed hypertension. Calcium for Preeclampsia Prevention Study Group. Obstet Gynecol. 2000;95(1):24-8.

4. Knuist M, Bonsel GJ, Zonderrvan HA, Treffers PE. Intensification of fetal and maternal surveillance in pregnant women with hypertensive disorders. Int J Gynecol Obstet. 1998;61:127-33.

5. Zoet GA, Koster MPH, Velthuis BK, De Groot CJM, Maas AHEM, Fauser BCJM, et al. Determinants of future cardiovascular health in women with a history of preeclampsia. Maturitas. 2015;82(2):153-61.

6. Pankiewicz K, Szczerba E, Maciejewski T, Fijałkowska A. Non-obstetric complications in preeclampsia. PrzMenopauzalny. 2019;18(2):99-109.

7. English FA, Kenny LC, McCarthy FP. Risk factors and effective management of preeclampsia. Integr Blood Press Control. 2015;8:7-12.

8. Mayrink J, Souza RT, Feitosa FE, Rocha Filho EA, Leite DF, Vettorazzi J, et al. Incidence and risk factors for preeclampsia in a cohort of healthy nulliparous pregnant women: a nested case-control study. Sci Rep. 2019; 9(1):9517.

9. Tranquilli AL, Brown MA, Zeeman GG, Dekker G, Sibai BM. The definition of severe and early-onset preeclampsia. Statements from the International Society for the Study of Hypertension in Pregnancy (ISSHP). Pregnancy Hypertens. 2013;3(1):44-7.

10. Moore LD, Le T, Fan G. DNA methylation and its basic function. Neuropsychopharmacology. 2013;38(1):23-38.

11. Gao WL, Li D, Xiao ZX, et al. Detection of global DNA methylation and paternally imprinted $\mathrm{H} 19$ gene methylation in preeclamptic placentas. Hypertens Res. 2011;34(5):655-61.

12. Kulkarni A, Chavan-Gautam P, Mehendale S, Yadav H, Joshi S. Global DNA methylation patterns in placenta and its association with maternal hypertension in pre-eclampsia. DNA Cell Biol. 2011;30(2):79-84.

13. Majchrzak-Celińska A, Kosicka K, Paczkowska J, et al. HSD11B2, RUNX3, and LINE-1 methylation in placental DNA of hypertensive disorders of pregnancy patients. Reprod Sci. 2017;24(11):1520-31.

14. White WM, Sun Z, Borowski KS, et al. Preeclampsia/eclampsia candidate genes show altered methylation in maternal leukocytes of preeclamptic women at the time of delivery. Hypertens Pregnancy. 2016;35(3):394-404.

15. Rahat B, Thakur S, Hamid A, Bagga R, Kaur J. Association of aberrant methylation at promoter regions of tumor suppressor genes with placental pathologies. Epigenomics. 2016:8(6):767-87.

16. Tsui DW, Chan KC, Chim SS, et al. Quantitative aberrations of hypermethylated RASSF1A gene sequences in maternal plasma in preeclampsia. Prenat Diagn. 2007;27(13):1212-8.

17. Bourque DK, Avila L, Peñaherrera M, von Dadelszen P, Robinson WP. Decreased placental methylation at the H19/IGF2 imprinting control region is associated with normotensive intrauterine growth restriction but not preeclampsia. Placenta. 2010;31(3):197-202.

18. White WM, Brost B, Sun Z, et al. Genome-wide methylation profiling demonstrates hypermethylation in maternal leukocyte DNA in preeclamptic compared to normotensive pregnancies. Hypertens Pregnancy. 2013;32(3): 257-69.

19. Van den Berg CB, Chaves I, Herzog EM, Willemsen SP, van der Horst GTJ, Steegers-Theunissen RPM. Early- and late-onset preeclampsia and the DNA methylation of circadian clock and clock-controlled genes in placental and newborn tissues. Chronobiol Int. 2017;34(7):921-32.

20. Apicella C, Ruano CSM, Méhats C, Miralles F, Vaiman D. The role of epigenetics in placental development and the etiology of preeclampsia. Int J Mol Sci. 2019;20:11.
21. Januar V, Desoye G, Novakovic B, Cvitic S, Saffery R. Epigenetic regulation of human placental function and pregnancy outcome: considerations for causal inference. Am J Obstet Gynecol. 2015;213(4 Suppl):S182-96.

22. Bianco-Miotto T, Mayne BT, Buckberry S, Breen J, Rodriguez Lopez CM, Roberts $\mathrm{CT}$. Recent progress towards understanding the role of DNA methylation in human placental development. Reproduction. 2016;152(1):R23-30.

23. Liberati A, Altman DG, Tetzlaff J, Mulrow C, Gøtzsche PC, loannidis JPA, et al The PRISMA statement for reporting systematic reviews and meta-analyses of studies that evaluate health care interventions: explanation and elaboration. PLoS Med. 2009;6(7):e1000100.

24. Stroup DF, Berlin JA, Morton SC, et al. Meta-analysis of observational studies in epidemiology: a proposal for reporting. Meta-analysis Of Observational Studies in Epidemiology (MOOSE) group. JAMA. 2000;283(15):2008-12.

25. American College of Obstetricians and Gynecologists; Task force on hypertension in pregnancy. Hypertension in pregnancy. Report of the American College of Obstetricians and Gynecologists' Task Force on Hypertension in Pregnancy. Obstet Gynecol. 2013;122(5):1122-31.

26. Brown MA, Magee LA, Kenny LC, et al. Hypertensive disorders of pregnancy: ISSHP classification, diagnosis, and management recommendations for international practice. Hypertension. 2018;72(1):24-43.

27. Report of the National High Blood Pressure Education Program Working Group on High Blood Pressure in Pregnancy. Am J Obstet Gynecol. 2000; 183(1):S1-S22.

28. Yuen RK, Pẽaherrera MS, von Dadelszen P, McFadden DE, Robinson WP. DNA methylation profiling of human placentas reveals promoter hypomethylation of multiple genes in early-onset preeclampsia. Eur J Hum Genet. 2010;18(9):1006-12.

29. Nomura Y, Lambertini L, Rialdi A, et al. Global methylation in the placenta and umbilical cord blood from pregnancies with maternal gestational diabetes, preeclampsia, and obesity. Reprod Sci. 2014;21(1):131-7.

30. Jia RZ, Zhang $X$, Hu P, et al. Screening for differential methylation status in human placenta in preeclampsia using a CpG island plus promoter microarray. Int J Mol Med. 2012;30(1):133-41.

31. Mousa AA, Archer KJ, Cappello R, et al. DNA methylation is altered in maternal blood vessels of women with preeclampsia. Reprod Sci. 2012; 19(12):1332-42.

32. Mousa AA, Cappello RE, Estrada-Gutierrez G, et al. Preeclampsia is associated with alterations in DNA methylation of genes involved in collagen metabolism. Am J Pathol. 2012;181(4):1455-63.

33. Mousa AA, Strauss JF 3rd, Walsh SW. Reduced methylation of the thromboxane synthase gene is correlated with its increased vascular expression in preeclampsia. Hypertension. 2012;59(6):1249-55.

34. Blair JD, Yuen RK, Lim BK, McFadden DE, von Dadelszen P, Robinson WP. Widespread DNA hypomethylation at gene enhancer regions in placentas associated with early-onset pre-eclampsia. Mol Hum Reprod. 2013;19(10):697-708.

35. Hogg K, Blair JD, McFadden DE, von Dadelszen P, Robinson WP. Early onset pre-eclampsia is associated with altered DNA methylation of cortisolsignalling and steroidogenic genes in the placenta. PLoS One. 2013;8(5): e62969.

36. Anderson CM, Ralph JL, Wright ML, Linggi $B$, Ohm JE. DNA Methylation as a biomarker for preeclampsia. Biol Res Nurs. 2014:16(4):409-20.

37. Anton L, Brown AG, Bartolomei MS, Elovitz MA. Differential methylation of genes associated with cell adhesion in preeclamptic placentas. PLoS One. 2014;9(6):e100148

38. Chu T, Bunce K, Shaw P, et al. Comprehensive analysis of preeclampsiaassociated DNA methylation in the placenta. PLoS One. 2014;9(9):e107318.

39. Liu L, Zhang $X$, Rong $C$, et al. Distinct DNA methylomes of human placentas between pre-eclampsia and gestational diabetes mellitus. Cell Physiol Biochem. 2014;34(6):1877-89.

40. Blair JD, Langlois S, McFadden DE, Robinson WP. Overlapping DNA methylation profile between placentas with trisomy 16 and early-onset preeclampsia. Placenta. 2014;35(3):216-22.

41. Ching $T$, Song MA, Tiirikainen $M$, et al. Genome-wide hypermethylation coupled with promoter hypomethylation in the chorioamniotic membranes of early onset pre-eclampsia. Mol Hum Reprod. 2014;20(9):885-904.

42. Anderson CM, Ralph JL, Johnson L, et al. First trimester vitamin D status and placental epigenomics in preeclampsia among Northern Plains primiparas. Life Sci. 2015:129:10-5.

43. Ching T, Ha J, Song MA, et al. Genome-scale hypomethylation in the cord blood dnas associated with early onset preeclampsia. Clin Epigenetics. 2015; $7(1): 21$ 
44. Martin E, Ray PD, Smeester L, Grace MR, Boggess K, Fry RC. Epigenetics and preeclampsia: defining functional epimutations in the preeclamptic placenta related to the TGF- $\beta$ pathway. PLoS One. 2015;10(10):e0141294.

45. Zhu L, Lv R, Kong L, Cheng H, Lan F, Li X. Genome-wide mapping of $5 \mathrm{mC}$ and $5 \mathrm{hmC}$ identified differentially modified genomic regions in late-onset severe preeclampsia: a pilot study. PLoS One. 2015;10(7):e0134119.

46. Xuan J, Jing Z, Yuanfang Z, et al. Comprehensive analysis of DNA methylation and gene expression of placental tissue in preeclampsia patients. Hypertens Pregnancy. 2016;35(1):129-38.

47. Kim JH, Cheong HS, Lee DS, Shin HD, Kim YN. Genome-wide DNA methylation profiles of maternal peripheral blood and placentas: potential risk factors for preeclampsia and validation of GRK5. Genes and Genomics. 2017:39(2):197-206.

48. Wilson SL, Liu Y, Robinson WP. Placental telomere length decline with gestational age differs by sex and TERT, DNMT1, and DNMT3A DNA methylation. Placenta. 2016;48:26-33.

49. Suzuki M, Maekawa R, Patterson NE, et al. Amnion as a surrogate tissue reporter of the effects of maternal preeclampsia on the fetus. Clin Epigenetics. 2016;8:67.

50. Yeung KR, Chiu CL, Pidsley R, Makris A, Hennessy A, Lind JM. DNA methylation profiles in preeclampsia and healthy control placentas. Am J Physiol Hear Circ Physiol. 2016;310(10):H1295-303.

51. Herzog EM, Eggink AJ, Willemsen SP, et al. Early- and late-onset preeclampsia and the tissue-specific epigenome of the placenta and newborn. Placenta. 2017;58:122-32.

52. Zhao M, Li L, Yang X, Cui J, Li H. FN1, FOS, and ITGA5 induce preeclampsia: abnormal expression and methylation. Hypertens Pregnancy. 2017;36(4): 302-9.

53. Wilson SL, Leavey K, Cox BJ, Robinson WP. Mining DNA methylation alterations towards a classification of placental pathologies. Hum Mol Genet 2018;27(1):135-46.

54. Wang $T$, Xiang $Y$, Zhou $X$, et al. Epigenome-wide association data implicate fetal/maternal adaptations contributing to clinical outcomes in preeclampsia. Epigenomics. 2019;11(9):1003-19.

55. Lu L, Hou Z, Li L, et al. Methylation pattern of $\mathrm{H} 19$ exon 1 is closely related to preeclampsia and trophoblast abnormalities. Int J Mol Med. 2014;34(3): 765-71.

56. Liu H, Tang Y, Liu X, et al. 14-3-3 tau (YWHAQ) gene promoter hypermethylation in human placenta of preeclampsia. Placenta. 2014;35(12): 981-8.

57. Shimanuki Y, Mitomi H, Fukumura $Y$, et al. Alteration of Delta-like ligand 1 and Notch 1 receptor in various placental disorders with special reference to early onset preeclampsia. Hum Pathol. 2015;46(8):1129-37.

58. Alahari S, Garcia J, Post M, Caniggia I. The von Hippel Lindau tumour suppressor gene is a novel target of E2F4-mediated transcriptional repression in preeclampsia. Biochim Biophys Acta Mol Basis Dis. 2018; 1864(10):3298-308

59. Li X, Wu C, Shen Y, et al. Ten-eleven translocation 2 demethylates the MMP9 promoter, and its down-regulation in preeclampsia impairs trophoblast migration and invasion. J Biol Chem. 2018;293(26):10059-70.

60. Sundrani DP, Reddy US, Joshi AA, et al. Differential placental methylation and expression of VEGF, FLT-1 and KDR genes in human term and preterm preeclampsia. Clinical Epigenetics. 2013;5(1):6.

61. Qi YH, Teng F, Zhou Q, et al. Unmethylated-maspin DNA in maternal plasma is associated with severe preeclampsia. Acta Obstet Gynecol Scand. 2015;94(9):983-8

62. Kim SY, Kim HJ, Park SY, Han YJ, Choi JS, Ryu HM. Early prediction of hypertensive disorders of pregnancy using cell-free fetal DNA, cell-free total DNA, and biochemical markers. Fetal Diagn Ther. 2016;40(4):255-62.

63. Hogg K, Blair JD, von Dadelszen P, Robinson WP. Hypomethylation of the LEP gene in placenta and elevated maternal leptin concentration in early onset pre-eclampsia. Mol Cell Endocrinol. 2013;367(1-2):64-73.

64. Lin L, Yu Y, Zhang Z, Yang Y. Significant hypomethylation of TNFAIP8 and increased expression in the placenta and peripheral blood cells from earlyonset preeclamptic patients. Int J Clin Exp Med. 2016;9(6):10384-93.

65. Müller HM, Ivarsson L, Schröcksnadel $H$, et al. DNA methylation changes in sera of women in early pregnancy are similar to those in advanced breast cancer patients. Clin Chem. 2004;50(6):1065-8.

66. Zhang $L$, Leng $M, L i Y$, et al. Altered DNA methylation and transcription of WNT2 and DKK1 genes in placentas associated with early-onset preeclampsia. Clin Chim Acta. 2019;490:154-60.
67. Wang Z, Lu S, Liu C, et al. Expressional and epigenetic alterations of placental matrix metalloproteinase 9 in preeclampsia. Gynecol Endocrinol. 2010;26(2):96-102

68. Czikk MJ, Drewlo S, Baczyk D, Adamson SL, Kingdom J. Dual specificity phosphatase 9 (DUSP9) expression is down-regulated in the severe preeclamptic placenta. Placenta. 2013;34(2):174-81.

69. Liu Q, Qiao FY, Shi XW, Liu HY, Gong X, Wu YY. Promoter hypomethylation and increased maspin expression in preeclamptic placentas in a Chinese population. Placenta. 2014;35(11):876-82.

70. Xiang $Y$, Cheng $Y$, Li X, et al. Up-regulated expression and aberrant DNA methylation of LEP and SH3PXD2A in pre-eclampsia. PLoS One. 2013;8(3): e59753.

71. Hall LM, Maden BE. Nucleotide sequence through the 18S-28S intergene region of a vertebrate ribosomal transcription unit. Nucleic Acids Res. 1980; 8(24):5993-6005.

72. Vlahos A, Mansell T, Saffery R, Novakovic B. Human placental methylome in the interplay of adverse placental health, environmental exposure, and pregnancy outcome. PLoS Genet. 2019;15(8):e1008236.

73. Kurdyukov S, Bullock M. DNA methylation analysis: choosing the right method. Biology (Basel). 2016;5(1):1-21.

74. Myatt L, Redman CW, Staff AC, et al. Strategy for standardization of preeclampsia research study design. Hypertension. 2014;63(6):1293-301.

75. Yung HW, Atkinson D, Campion-Smith T, Olovsson M, Charnock-Jones DS, Burton GJ. Differential activation of placental unfolded protein response pathways implies heterogeneity in causation of early- and late-onset preeclampsia. J Pathol. 2014;234(2):262-76.

76. Konwar C, Del Gobbo G, Yuan V, Robinson WP. Considerations when processing and interpreting genomics data of the placenta. Placenta. 2019; 84:57-62.

77. Chakrabarti J, Turley H, Campo L, et al. The transcription factor DEC1 (stra13, SHARP2) is associated with the hypoxic response and high tumor grade in human breast cancers. Br J Cancer. 2004;91(5):954-8.

78. Baumann MU, Zamudio S, Illsley NP. Hypoxic upregulation of glucose transporters in BeWo choriocarcinoma cells is mediated by hypoxiainducible factor-1. Am J Physiol Cell Physiol. 2007;293(1):C477-85.

79. Kuc S, Wortelboer EJ, van Rijn BB, Franx A, Visser GH, Schielen PC. Evaluation of 7 serum biomarkers and uterine artery Doppler ultrasound for firsttrimester prediction of preeclampsia: a systematic review. Obstet Gynecol Surv. 2011;66(4):225-39.

80. Shibuya M. Vascular endothelial growth factor (VEGF) and its receptor (VEGFR) signaling in angiogenesis: a crucial target for anti- and proangiogenic therapies. Genes Cancer. 2011;2(12):1097-105.

81. Michels KB, Binder AM, Dedeurwaerder $\mathrm{S}$, et al. Recommendations for the design and analysis of epigenome-wide association studies. Nat Methods. 2013;10(10):949-55.

82. Valensise H, Vasapollo B, Gagliardi G, Novelli GP. Early and late preeclampsia: two different maternal hemodynamic states in the latent phase of the disease. Hypertension. 2008;52(5):873-80.

83. Michels KB, Binder AM. Considerations for design and analysis of DNA methylation studies. Methods Mol Biol. 2018;1708:31-46.

84. Hogg K, Price EM, Robinson WP. Improved reporting of DNA methylation data derived from studies of the human placenta. Epigenetics. 2014;9(3):333-7.

85. Waterland RA, Michels KB. Epigenetic epidemiology of the developmental origins hypothesis. Annu Rev Nutr. 2007;27:363-88.

86. Zhang Y, Kutateladze TG. Diet and the epigenome. Nat Commun. 2018;9(1):3375.

87. Ma X, Li J, Brost B, Cheng W, Jiang SW. Decreased expression and DNA methylation levels of GATAD1 in preeclamptic placentas. Cell Signal. 2014; 26(5):959-67.

88. Florath I, Butterbach K, Müller H, Bewerunge-Hudler M, Brenner H. Crosssectional and longitudinal changes in DNA methylation with age: an epigenome-wide analysis revealing over 60 novel age-associated CpG sites. Hum Mol Genet. 2014;23(5):1186-201.

89. Cavazos-Rehg PA, Krauss MJ, Spitznagel EL, et al. Maternal age and risk of labor and delivery complications. Maternal Child Health J. 2015;19(6):1202-11.

90. Martin E, Smeester L, Bommarito PA, et al. Sexual epigenetic dimorphism in the human placenta: implications for susceptibility during the prenatal period. Epigenomics. 2017;9(3):267-78.

91. Acharya A, Brima W, Burugu S, Rege T. Prediction of preeclampsia-bench to bedside. Curr Hypertens Rep. 2014;16(11):491.

92. Novakovic B, Yuen RK, Gordon L, et al. Evidence for widespread changes in promoter methylation profile in human placenta in response to increasing 
gestational age and environmental/stochastic factors. BMC Genomics. 2011; 12:529.

93. Reed K, Poulin ML, Yan L, Parissenti AM. Comparison of bisulfite sequencing PCR with pyrosequencing for measuring differences in DNA methylation. Anal Biochem. 2010;397(1):96-106.

94. Hernández HG, Tse MY, Pang SC, Arboleda H, Forero DA. Optimizing methodologies for PCR-based DNA methylation analysis. Biotechniques. 2013;55(4):181-97.

95. Nakabayashi K. Illumina HumanMethylation BeadChip for genome-wide DNA methylation profiling: advantages and limitations. In: Patel V, Preedy V, editors. Handbook of Nutrition, Diet, and Epigenetics. Cham.: Springer; 2018. p. 1-15.

96. Chen YA, Lemire M, Choufani S, et al. Discovery of cross-reactive probes and polymorphic CpGs in the Illumina Infinium HumanMethylation450 microarray. Epigenetics. 2013:8(2):203-9.

97. Barros-Silva D, Marques CJ, Henrique R, Jerónimo C. Profiling DNA methylation based on next-generation sequencing approaches: new insights and clinical applications. Genes (Basel). 2018;9(9):429.

98. Tak YG, Farnham PJ. Making sense of GWAS: using epigenomics and genome engineering to understand the functional relevance of SNPS in non-coding regions of the human genome. Epigenetics Chromatin. 2015;8: 57.

\section{Publisher's Note}

Springer Nature remains neutral with regard to jurisdictional claims in published maps and institutional affiliations.

Ready to submit your research? Choose BMC and benefit from:

- fast, convenient online submission

- thorough peer review by experienced researchers in your field

- rapid publication on acceptance

- support for research data, including large and complex data types

- gold Open Access which fosters wider collaboration and increased citations

- maximum visibility for your research: over $100 \mathrm{M}$ website views per year

At BMC, research is always in progress.

Learn more biomedcentral.com/submissions 